WORK IN PROGRESS

\title{
Design of serious games to assist the reading comprehension of technical texts
}

\author{
Juan Carlos Avilés-Díaz, María Susana Avila-Garcia
}

Published: 31 October 2018

\begin{abstract}
Reading comprehension of technical texts is a very important skill that engineering students need to develop. One of the first encounters of engineering students with technical texts in English occurs in programming activities when using a $\mathrm{C} / \mathrm{C}++$ compiler, and errors are produced at compilation time. In this work, we present preliminary results of the design of serious games to assist reading comprehension of $\mathrm{C}$ compiling errors. We designed and evaluated low fidelity prototypes of games designed so that players can improve their reading comprehension skills at the micro-, and macro-level, i.e. focusing on technical vocabulary, and providing solutions and interpretations to the errors shown in the games. We evaluated the games to learn about their acceptability and whether the students would play them again.
\end{abstract}

Keywords: Experimental design, Multi-touch applications, Interaction Design, Low-Fidelity Prototypes.

\section{Introduction}

The English language is one of the most used for communication between individuals of different cultures. Being able to understand and communicate in English has become so important that in Mexico it is taught as a second language from primary to high level education [6]. However, in traditional English courses technical vocabulary has received little attention.

Engineering students at the University of Guanajuato in Yuriria need to develop programming skills as part their educational program. Introduction to programming in the $\mathrm{C}$ language is taught in one of the initial courses of their career. Understanding errors thrown by the $\mathrm{C}$ compilers is one of the challenges for novice programmers since these are presented in English. When students of an introductory $\mathrm{C}$ programming course were faced with an error text thrown by the compiler, they ask the instructor about the error, or try and identify a key element within the text to solve the issue [8]. Understanding an error text enables students to be autonomous and to solve them.

\section{Serious games}

Serious games are intended to teach, motivate, and encourage participants to follow a learning process. Serious games are

\footnotetext{
Aviles-Diaz, JC., Avila-Garcia, MS.

Universidad de Guanajuato

Yuriria, Guanajuato, México

Email: jc.avilesdiaz@ugto.mx,susana.avila@ugto.mx
}

designed following the gamification principles, based on 7 main concepts such as point scoring, defining levels of complexity, attracting the attention of the participants, introducing them to the game and achieving a positive response from them [7].

Serious games have been proposed in education in medicine [2], engineering [3], software engineering [5], etc. In this work, we propose the use of serious games to address the reading comprehension by Spanish native speakers of $\mathrm{C}$ compiling errors in English. In the long term, we aim to develop multi-touch applications to allow students to learn in a collaborative way, using more intuitive interfaces to provide a better user experience. Given that the development of these types of applications require considerable time and effort, the design and evaluation of lowfidelity (low-fi) prototypes is a way to reduce the risk of unnecessary developments. This is a work in progress and we show preliminary results of the evaluation of low-fi prototypes that can serve as a basis for further developments of high-fidelity prototypes in $\mathrm{C \#}$ and WPF.

\section{Game design}

Five different games were designed. The content of the games was defined by analysing a database of $\mathrm{C}$ compiler errors reported by a group of students in a class where students get an introduction to $\mathrm{C}$ programming. This database was previously used in [4]; where serious games designed using Intuiface Composer for a multi-touch table top were reported.

The games were designed following classic board games where participants could interact with each of the games. Furthermore, we took into consideration the recommendations made in [9] about the characteristics that a serious game should contain, including:

- Accumulation of points: Quantitative values are assigned to certain actions or achievements.

- Level scaling: A series of levels is defined that the user must overcome.

- Obtaining prizes: as the user achieves different goals, prizes are awarded.

- Gifts: These are goods that are given to the player when obtaining fixed objectives.

- Classifications: Classify users based on points earned or prizes won.

- Encounters: These are competitions among users.

- Challenges: To solve a raised challenge, alone or as a team. Furthermore, games were designed to assist the reading comprehension at a micro- and macro- levels. Micro-level means focusing on words or understanding vocabulary. Macro-level 
focusses on a deep understanding of a text, for instance, explaining what the text is about. In this case, we consider that a student comprehends a $\mathrm{C}$ compiler error at the macro level if he/she can explain the error and fix the $\mathrm{C}$ code.

\section{Experimental design}

\subsection{Materials}

- Video Camera

- Tripod

- Low Fidelity Games

- Consent letters

- Timer

- Evaluation forms

\subsection{Participants}

Eight participants were recruited to evaluate the low-fi prototypes of the games. They were students who had already attended the fundamentals of information systems course and have used the Dev C ++ compiler. They have a minimum level of English of 2 (according to the levels offered by the University of Guanajuato).

\subsection{Activity}

First, the aim of the experiment was explained to each participant and consent forms to record the session on video were signed. The games were played and at the end of each game the participant was asked to provide feedback regarding the characteristics of the game, if they would play it again, and if they had learned something.

\subsubsection{Game 1: Show me my Name}

In this game, the player was shown 6 images of punctuation marks needed as part of the $\mathrm{C}$ language syntax and whose names students need to learn in English. These include:

- A parenthesis

- A semicolon

- A colon

- Curly brackets

- Square brackets

- Quotes

In this game, participants were asked to overlap the image of the punctuation marks to the corresponding name. When the participant is ready for evaluation, and then a question mark placed on their right hand side is touched. The instructor evaluates the responses and awards points depending on the number of hits and the time spent during the activity.

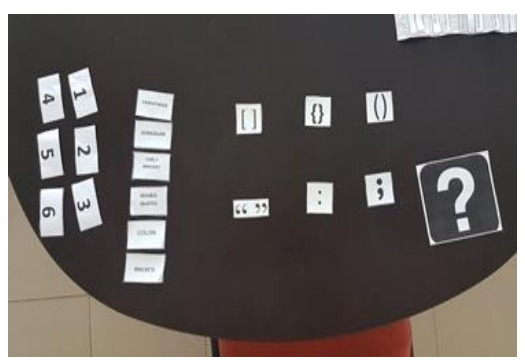

Figure 1. Items of the Game 1, "Show me my Name".

\subsubsection{Game 2: Matching Pairs}

The second game, shown in Figure 2, is based on a well-known game called Matching Pairs. In this activity four pairs of errors and solutions randomly ordered were placed facing down, so that the participants had to flip each card and look for their respective match. When the participants believed they were correct, they were asked to touch a question mark placed on their right-hand side. Then the instructor would verify if the pairs the participant had chosen were correct, if so, a number of points were awarded depending on whether the answer was correct or incorrect and the time spent. The game ended as soon as the player concluded with all the pairs correctly, resulting in a score weighted by the time played (each minute a point was subtracted) and the points obtained by the correct answers. Players could see the score in a board table where results are shown to all players.

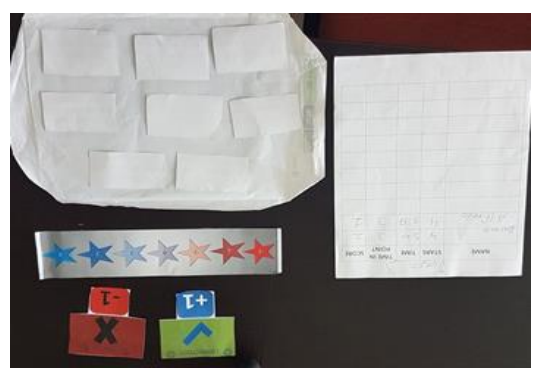

Figure 2. Items of the Game 2, "Matching Pairs".

\subsubsection{Game 3: True or False}

In this game, shown in Figure 3, the participant is asked to place a card, reporting a piece of code and the corresponding compiler evaluation, on top of "True" or "False" cards available. Points were awarded as follows: first questions had a value of one point, the second question a value of two, and finally, the third question a value of three points, to give the participants the chance to recover in case they have failed the first two attempts.

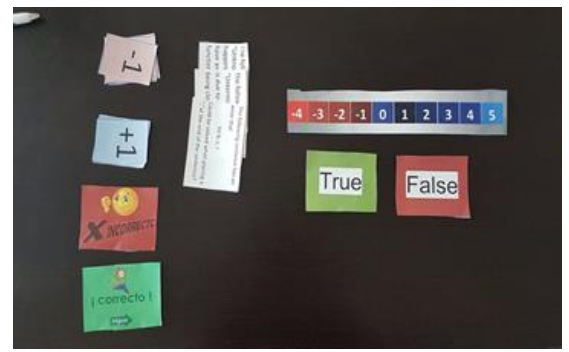

Figure 3. Items of the Game 3, "True or False".

\subsubsection{Game 4: Find and remove the error}

In the fourth game, shown in Figure 4, participants were shown a small fragment of a code that when compiled generates 6 different errors located in different lines. Participants were shown the code for 20 seconds and then a card with a specific error, and they were asked to find where the error was located; then, they were shown 3 cards, each one with a possible solution, and were asked to select the card with the correct solution. If the participants selected their response well on the first try they were given 3 points, on the second attempt they were 2 points and on the third attempt they lost the game. Funny images were shown in cards to announce the participants the result of their choice. For a correct answer, an image that showed the word congratulations and an image of joy were displayed. If the answer was correctly given on the second attempt the message shown was "Until you finally succeeded", and those answering correctly on the third attempt, were shown a card with an image of disappointment that said "You're wrong, keep trying", and finally, on the fourth card was an image of denial and defeat. These messages were used to observe the participant's reactions and add design features to 
make the games funnier and motivate participants to play the game again in the future.

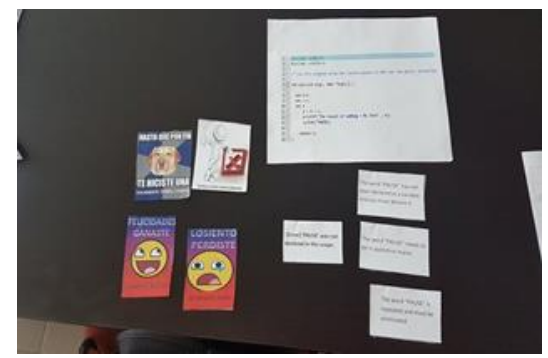

Figure 4. Items of the Game 4, "Find and Remove the Error".

\subsubsection{Game 5: Find Errors}

Game 5 is a variation of Game 4. In this game, only 5 different errors are introduced in a piece of code, but participants are given 18 message errors, from which only 4 describe actual errors in the code. When the errors are identified the participants, they are asked to touch a question-mark placed on the right side. The instructor provides feedback to the participant showing the number of correct answers. The game continues until the participant has the 4 correct answers, or when the time limit of 8 minutes is reached.

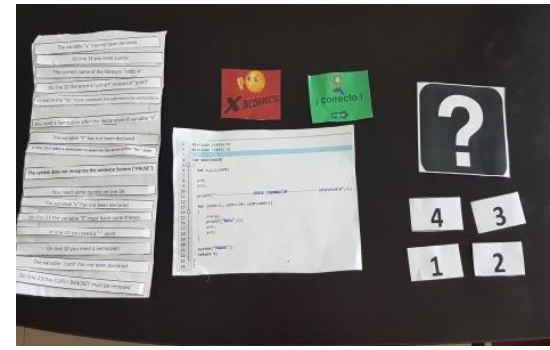

Figure 5. Items of the Game 5, "Find Errors".

\section{Results and future work}

Preliminary results show that participants found the games interesting. The first game was not as challenging as the second one, where some of them struggle a little bit more. However, participants found the third game easy and simple, and this was consistent with the short time it took the participants to conclude the game. The fourth and fifth game turned out to be their favourite games as these motivated them to think more and to include fragments of code in a visible image and not only errors shown on cards, these games made them more familiar with their experience in class and at the same time they felt it was more entertaining.

The data obtained, including the video, need to be analysed in detail. In addition, there will be a redesign of the games taking into account the comments provided by the participants and the results of the surveys conducted. The analysis of the data and the feedback provided by the participants will be considered in the design of a high level prototype, which will be developed using Visual C\# and WPF. The development of the interactive games will be implemented in a multi-touch screen 3M model C4667PW of 46", which when used as an interactive table top can assist collaborative learning [3].

\section{Acknowledgments}

We thank all the participants for their time. This work was supported by the SEP-PRODEP grant UGTO-PTC-510.

\section{References}

[1] "Consultoría De Selección: Profesionales Alto Nivel." Randstad. N.p. 2009. Web. 29 June 2018. Retrieved June 25, 2018 from https://www.randstad.es/nosotros/sala-prensa/elconocimiento-de-idiomas-aumenta-un-37-las-posibilidadesde-encontrar-empleo/

[2] Gorbanev, I., Agudelo-Londoño, S., González, R. A., Cortes, A., Pomares, A., Delgadillo, V., Muñoz, Ó. (2018). A systematic review of serious games in medical education: quality of evidence and pedagogical strategy. Medical Education Online, 23. Web. 1 July 2016. Retrieved June 25, 2018 https://doi.org/10.1080/10872981.2018.1438718

[3] Hauge, J. B., Pourabdollahian, B., \& Riedel, J. C. K. H. (2013). The Use of Serious Games in the Education of Engineers. Advances in Production , 397(Part I), 622-629. Web. 29 June 2018. Retrieved August 25, 2018 from https://doi.org/10.1007/978-3-642-40352-1_78

[4] Imbrett, S, M \& Ávila, G, M, S (2017). Diseño de juegos interactivos y multitáctiles para la enseñanza del inglés. Veranos de la investigación Científica, Vol. 3, no. 2, 2017.

[5] Jiménez-hernández, E. M., Piattini, M., \& Oktaba, H. (2017). Serious Games when used to Learn Software Processes: An Analysis from a Pedagogical Perspective. Web. Retrieved September 04, 2018 from https://doi.org/10.1109/CONISOFT.2017.00031

[6] "La Importancia Del Idioma Inglés En El Mundo Moderno| E3 English." N.p., 2017. Web. Retrieved June 19, 2018 from https://e3english.com/la-importancia-del-idioma-ingles/

[7] "Manejo De Ambientes (Desarrollo, Testeo, Preproduccion, Producción)." Wiki.genexus.com. N.p., 2018. Web Retrieved July 9, 2018 from

https://wiki.genexus.com/commwiki/servlet/wiki?29683,Man ejo+de+ambientes+\%28Desarrollo\%2C+Testeo $\% 2 \mathrm{C}+$ PrePro duccion $\% 2 \mathrm{C}+$ Producci\%C3\%B3n\%29.

[8] Mejia-Sierra MY. Diseño de un Sistema de Información para Asistir la Definición de Estrategias para la Comprensión de Textos Técnicos en Inglés. Universidad de Guanajuato, 2017.Serrano Laguna, Ángel, and Baltasar Fernández Manjón. Mejorando La Evaluación De Juegos Serios Mediante El Uso De Analíticas De Aprendizaje. 2017. Print.

[9] Teixes, Ferran. Gamificación: Fundamentos Y Aplicaciones. Universitat Oberta de Catalunya, 2014. Print. 